\title{
Dispersal and reproductive careers of male mountain gorillas in Bwindi Impenetrable National Park, Uganda
}

\author{
Martha M. Robbins ${ }^{1}$ (D) . Moses Akantorana ${ }^{1}$. Joseph Arinaitwe ${ }^{2} \cdot$ Peter Kabano $^{1}$. Charles Kayijamahe ${ }^{3}$. \\ Maryke Gray ${ }^{3} \cdot$ Katerina Guschanski ${ }^{1,4}$. Jack Richardson ${ }^{1} \cdot$ Justin Roy ${ }^{1} \cdot$ Vastine Tindimwebwa $^{2} \cdot$ Linda Vigilant $^{1}$. \\ Andrew M. Robbins ${ }^{1}$
}

Received: 30 September 2018 / Accepted: 10 February 2019 / Published online: 7 March 2019

(c) The Author(s) 2019

\begin{abstract}
Dispersal is a key event in the life of an animal and it influences individual reproductive success. Male mountain gorillas exhibit both philopatry and dispersal, resulting in a mixed one-male and multimale social organization. However, little is known about the relationship between male dispersal or philopatry and reproductive careers in Bwindi mountain gorillas. Here we analyze data spanning from 1993 to 2017 on social groups in Bwindi Impenetrable National Park, Uganda to examine the proportion of males that disperse, age of dispersal, pathways to attaining alpha status, fate of dispersing males and philopatric males, and male tenure length as well as make comparisons of these variables to the Virunga mountain gorilla population. We report previously undocumented cases of dispersal by immature males and old males and we also observed the only known case of a fully mature male immigrating into a breeding group. We used genetic tracking of known individuals to estimate that a minimum of $25 \%$ of males that disperse to become solitary males eventually form new groups. No differences were found between the Bwindi and Virunga population in the age of male dispersal, the proportion of males that disperse, the age of alpha male acquisition, and dominance tenure length. The lack of differences may be due to small sample sizes or because the observed ecological variability does not lead to life history differences between the populations. Males in both populations follow variable strategies to attain alpha status leading to the variable one-male and multimale social organization, including dispersal to become solitary and eventually form a group, via group fissioning, usurping another alpha male, or inheriting the alpha position when a previous group leader dies.
\end{abstract}

Keywords Dispersal $\cdot$ Philopatry $\cdot$ Solitary male $\cdot$ Dominance transitions $\cdot$ Alpha status

\section{Introduction}

Dispersal is a key event in the life of an animal because of the linkages to population dynamics, life history strategies, genetic and social structuring of a population, and variance in reproductive success (Dobson 2013; Greenwood 1980).

Andrew M. Robbins

robbins@eva.mpg.de

1 Max Planck Institute for Evolutionary Anthropology, Deutscher Platz 6, 04103 Leipzig, Germany

2 Uganda Wildlife Authority, PO Box 3530, Kampala, Uganda

3 International Gorilla Conservation Program, P.O. Box 931, Kigali, Rwanda

4 Present Address: Animal Ecology, Department of Ecology and Genetics, Evolutionary Biology Centre, Uppsala University, Norbyvägen 18D, 75236 Uppsala, Sweden
Dispersal decisions and dispersal distance are influenced by many factors including reproductive opportunities, risk of inbreeding, competition for resources, and ecological conditions (Clutton-Brock 2016; Gilroy and Lockwood 2012). Furthermore, the future success of dispersing individuals may vary, depending on the age at dispersal as well as the opportunities to acquire mates outside of the natal group (Clutton-Brock 2016; Davidian et al. 2016).

In social living species, such as primates, dispersal patterns result in within- and between-species variation in social organization (Chapman and Rothman 2009; Kappeler and van Schaik 2002; Pusey and Packer 1987). Despite most primate species exhibiting universal male dispersal (Pusey and Packer 1987), some species have universal male philopatry (Furuichi et al. 2015) or both philopatry and dispersal (Chowdhury et al. 2015; Koenig and Borries 2012; Ostro et al. 2001; Port et al. 2012; Sterck 1999). In primates, 
components of maturation and male dispersal patterns can have implications for the reproductive careers and variance in reproductive success of individual males (Alberts 2012; Alberts and Altmann 1995; Port et al. 2012; van Noordwijk and van Schaik 2001, 2004). For example, in societies where male rank influences reproductive success, dispersal strategies may be determined by the viability of attaining the alpha position via tactics such as challenging a current dominant male, forming a new group by attracting females, or a group fission (van Noordwijk and van Schaik 2004).

Mountain gorillas are an interesting species in which to examine patterns of male dispersal and reproductive careers because they exhibit both philopatry and dispersal, which may lead to variation in male reproductive success (Harcourt 1978; Robbins 1995; Robbins et al. 2009a, b; Stoinski et al. 2009a). In contrast, male western gorillas appear to have universal male dispersal (Robbins et al. 2016). Because multimale groups form as a result of male philopatry and not takeovers by outsider males, multimale groups in western gorillas are extremely rare in comparison to both mountain gorilla populations that contain about $40 \%$ multimale groups (Robbins et al. 2016; Robbins, 1995; Robbins et al. 2009b). Variation in male dispersal patterns has implications for group structure and possible variation in male tenure length and reproductive success between the two species (Robbins and Robbins 2018).

For male mountain gorillas, the first decision of their reproductive career is whether to disperse or remain philopatric (Fig. 1). Dispersal includes males who emigrate to become solitary, as well as males who leave their group with other gorillas as part of a group fission (Stoinski et al. 2009a). Dispersal also includes involuntary transfers, in which an immature male joins a new group following the disintegration of his previous group, typically due to the death of the silverback. Solitary males may subsequently form one-male groups by attracting females from established groups. Philopatric males may become alpha by usurping the current alpha male, inheriting the alpha position following the death of a previously alpha male, or alternatively they can remain subordinate (Fig. 1). In the Virunga mountain

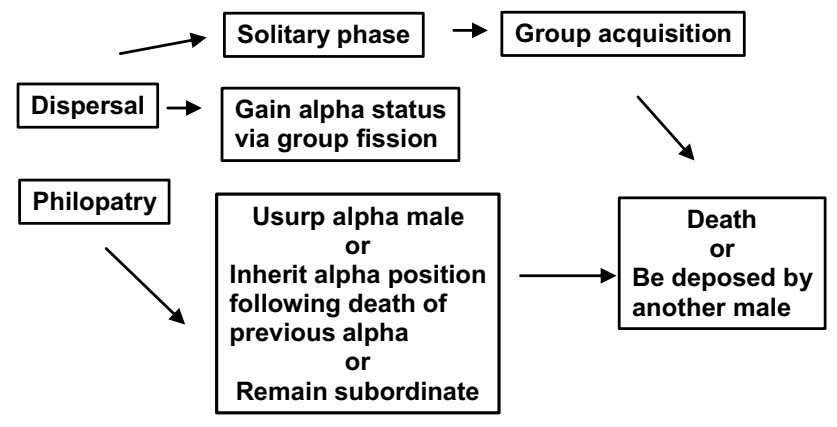

Fig. 1 Trajectory of male reproductive career for mountain gorillas gorilla population, philopatric males had higher lifetime reproductive success than dispersing males, suggesting that philopatry appears to be a more beneficial strategy, yet some males still disperse (Robbins and Robbins 2005; Watts 2000). The probability of male emigration does not appear to be influenced by the number of potential mates in the group, the number of potential competitors, or the age of dominant male (Stoinski et al. 2009a; Watts 2000). Instead, mating opportunities and the presence of mothers may lead to male philopatry (Robbins et al. 2016; Stoinski et al. 2009a, b).

The habitats and diets of the two remaining populations of mountain gorillas (Virunga Massif and Bwindi Impenetrable National Park, Uganda) are different, largely due to altitudinal variation (Robbins et al. 2006b; Wright et al. 2015). The mountain gorillas in the Virunga Massif consume almost no fruit because there is so little available and nearly all of their dietary items are available year-round. In contrast, Bwindi is lower altitude, so it contains more seasonally available (and less predictable in availability) fruit and the gorillas' diet is roughly $10-15 \%$ fruit. The 'risk aversion hypothesis' predicts that an increase in the seasonality of food resources leads to slower life histories (Janson and van Schaik 1993). The risk aversion hypothesis was developed to explain the slow life histories of primates in general, as well as variation in life history parameters within and between species. It is based on the premise that mortality risk for juvenile primates is high due to risk of starvation and predation, resulting in slow growth rates to reduce the risk of starvation, such that as variation in food availability increases, the risk increases, so slower growth is expected (Janson and van Schaik 1993). Life history studies have shown that ecological variation can explain variation in female reproductive rates, age of first reproduction, and adult lifespan (Onyango et al. 2013; Pusey 2012), but the same principles could apply to male dispersal and reproductive careers (Alberts 2012). The ecological variation between Bwindi and the Virungas could explain why the interbirth interval is 5 years in Bwindi compared to 4 years in the Virungas (Robbins et al. 2009b; Wright et al. 2015). The inter-population ecological variation could also lead to variation in certain life history traits such as age of maturation, the proportion of males that disperse, the age of dispersal and alpha rank acquisition, and tenure lengths. Longer alpha male tenures could indicate a slower life history, or differences in the intensity of mating competition.

Relatively little is known about the life history patterns of male mountain gorillas in Bwindi (Robbins et al. 2009b), so the aims of this paper are to characterize the dispersal patterns and reproductive careers for Bwindi mountain gorillas and compare these with published information from the Virunga mountain gorillas. Specifically, we quantify the age and proportion of dispersing immature and mature males, the fate of solitary males, age of acquiring alpha male status and tenure length. We used the long-term demographic 
database from the habituated gorilla groups in Bwindi spanning 1993-2017. Furthermore, assessing the fate of solitary males, specifically when and if they form a group or die, is notoriously difficult because it is not feasible to continue to monitor them over a long time period. Therefore we use genetic data obtained from the 2006 and 2011 mountain gorilla censuses to track whether the emigrant males were still solitary after 5 years or had attained a group (Guschanski et al. 2009; Roy et al. 2014).

\section{Methods}

\section{Study population and data collection}

This study was conducted in Bwindi Impenetrable National Park, located in the southwest corner of Uganda $\left(0^{\circ} 53^{\prime}-1^{\circ} 08^{\prime} \mathrm{N} ; 29^{\circ} 35^{\prime}-29^{\circ} 50^{\prime} \mathrm{E}\right)$. The "main" dataset includes information that was collected from 1993 to 2017 from seven gorilla groups that have been habituated for tourism and research, and two solitary males who were monitored for a few months after leaving their groups (Fig. 2). Four groups (Ka, $\mathrm{Mu}, \mathrm{Ru}$, and Haa) ranged around Buhoma in the western section of the park, two groups (Ky and Bit) ranged near Ruhija in the eastern section of the park, and one group (Nk) ranged in the southwest (Robbins et al. 2009b; Seiler et al. 2018). These groups were monitored daily, allowing for accurate recording of all births, deaths, and dispersal events. In addition to the main dataset, an "expanded" dataset includes six other habituated groups that were monitored from 2008 to 2017, but the exact group compositions were not known and demographic events were not systematically recorded (Fig. 2). Those groups are used only in analysis of dominance tenures.

For this study, we used the same age categories as those used for Virunga mountain gorillas (Robbins et al. 2006a). Infants are defined as those gorillas $<3$ years old, juveniles are 3-5 years of age, and subadults are 6-7 years old. Females are considered adult at age 8 years. Males between 8 and 11 years are classified as blackbacks, and those $12+$ years old are called adult males or silverbacks. Immatures are defined as the sum of infants, juveniles, and subadults (Kalpers et al. 2003). Because many gorillas were born before their groups were habituated, the exact birth dates are not known for all individuals. For any analyses using the age of males, we restrict the dataset to individuals whose birthdate was estimated to the nearest 6 months (Robbins et al. 2009b).

Emigration was defined as the age when the male "was no longer observed in their group and had ceased making repeated visits to the group lasting more than 1 day" (Stoinski et al. 2009a). An involuntary transfer occurred when a male joined a new group following the disintegration of his previous group, typically due to the death of the silverback. Dispersal included males who emigrated to become solitary and those who left in a group fission. Philopatry included males who died or became dominant in the group after reaching age 12 . Philopatry does not include males who were still subordinate at the end of observations because it was not known whether they would subsequently disperse,
Fig. 2 Timelines of groups included in the study. The year of the study is denoted on the $x$-axis. Each bar on the year axis represents a different study group and when they were observed. Blue coloring indicates when groups were multimale and purple indicates when they were one-male. Orange denotes when a group was an all-male group. Solid black vertical lines indicate when a group fissioned into two groups

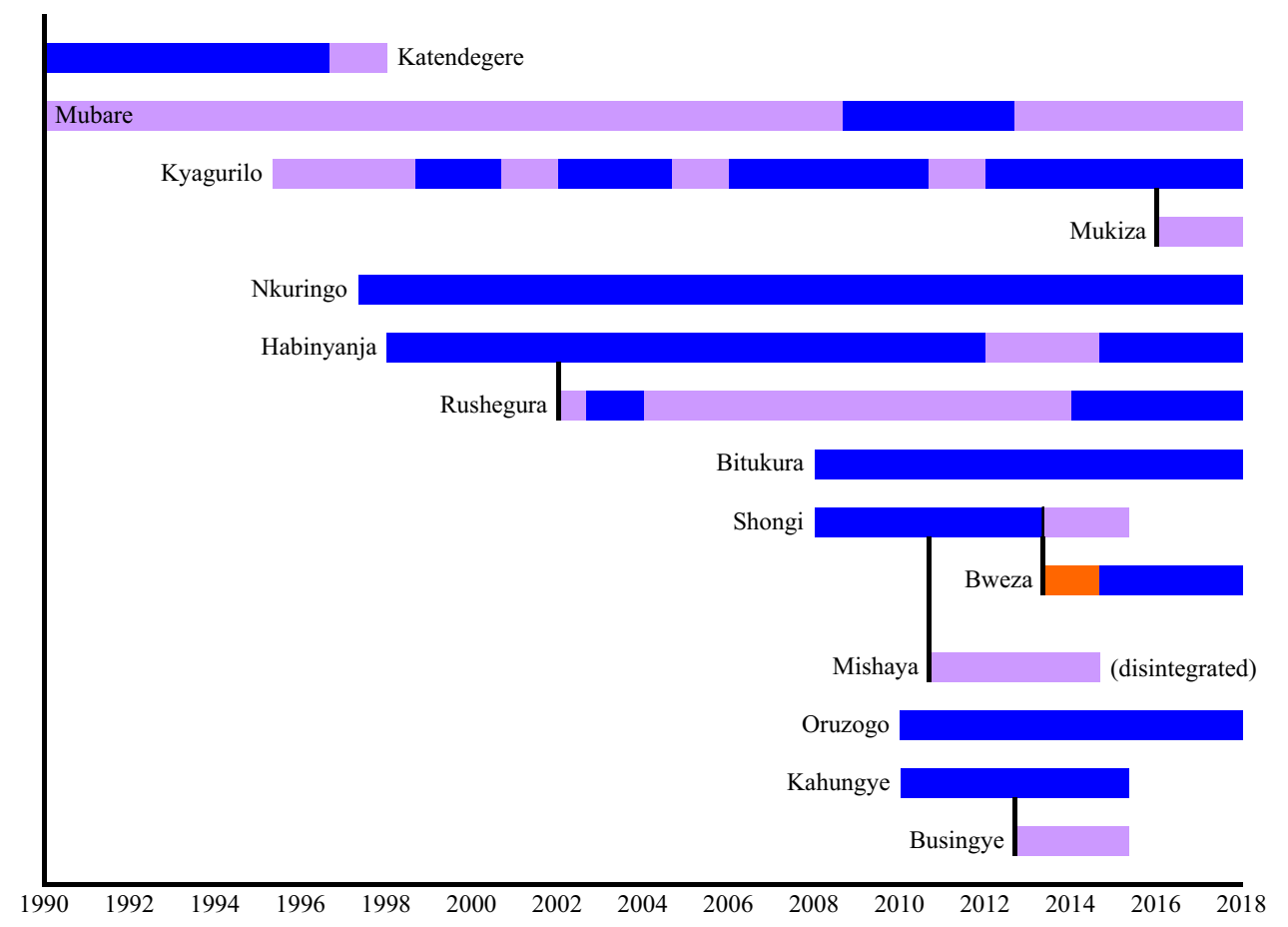


become dominant without dispersal, or remain subordinate until their death. All statistical results for young silverbacks are based on the assumption that unexplained disappearances were due to emigration. Results were similar when we assumed that the unexplained disappearances were due to death.

In addition to direct observations of habituated groups, we also used genotype data from population-wide censuses to track individuals that were found as solitary males or in groups in the 2006 census and subsequently found in the 2011 census as solitary males or in a different social unit (Guschanski et al. 2009; Nsubuga et al. 2008; Roy et al. 2014). The number of gorillas in Bwindi Impenetrable National Park was estimated in 2006 and 2011 by means of 'sweep' census efforts to survey the entire park for detection of 'nests' constructed in the evening by individual gorillas (Guschanski et al. 2009; Roy et al. 2014). Dung left in the nests was collected for genetic analysis, and gorilla counts were based on a combination of nest count data and genetic data. DNA extracted from the fecal samples was used to produce individually specific genetic profiles by means of microsatellite genotyping, as previously detailed. We compared all genotypes from the 2006 and 2011 censuses to detect movement of males from one social group to another, or from solitary to social group or vice versa.

\section{Statistical analyses}

We used a generalized linear mixed model (GLMM; Jiang 2007) to compare the ratio of dispersal:philopatry among young silverbacks at Bwindi versus the Virungas. The model was run with a binomial error structure and logit link. The analysis used one data point for each male who dispersed or remained philopatric during the study. The response variable equaled " 1 " if the male dispersed and " 0 " if he was philopatric. The predictor variable was the gorilla population, and the model included a random effect variable for the group that the gorilla left.

To determine if the proportion of males that emigrated to become solitary differed between populations, we used a similar GLMM to compare the ratio of males who emigrated versus those who became dominant without emigration (e.g., males that formed a group via fissioning were not considered emigrants). The response variable equaled " 1 " if the male emigrated and " 0 " if he became dominant without emigrating to become solitary. Males could become dominant by inheriting or usurping the dominant role, or through group fission. We excluded males that did not remain dominant long enough to sire any offspring.

To compare the age of emigration between Bwindi and the Virungas, we ran a GLMM with one data point for each emigrant, with the response variable being the age of emigration. The predictor variable was the gorilla population, and the model included a random effect variable for the group that the gorilla left.

To compare the ages at which subordinate males became dominant, we ran a GLMM with one data point for each young silverback who inherited or usurped the dominant role in his group, as well as males who became dominant through a group fission. The analysis excluded solitary males who became dominant by acquiring females because such males are not monitored routinely and we do not have data on when they became dominant. The response variable was the age of becoming dominant; the predictor variable was the gorilla population; and the model included a random effect variable for the group where the gorilla had been subordinate.

To compare the probability of remaining subordinate (versus age), we used a mixed effect Cox model (Pankratz et al. 2005). The analysis used a separate data point for each male who was observed to reach age 12 . The predictor variable was the gorilla population, and the model included a random effect variable for the group where the gorilla had been subordinate. Uncensored data points equaled the normalized age when males emigrated, became dominant, or died. Data points were censored if males were still subordinate when the study ended. The Bwindi data were compared with published results from Karisoke study area of the Virungas (Stoinski et al. 2009a) that included males living in a mixed-sex group at the time they became silverbacks and whose birthdates were estimated to the nearest month (12 years of age; $N=31$ ).

Using the genetic tracking data, we investigated if success rates of solitary males forming groups increased over time, which would suggest that they need to continue maturing after dispersal, as Karisoke males continue to grow until about 16 years of age (Galban et al. 2017). Conversely, if the success rate declined over time, it might suggest that high-quality males succeed more quickly than lower quality males. To do this, we performed a Fisher's exact test to compare the frequency of males that were solitary in 2006 and in a mixed sex group in 2011 (presumed dominant male) versus males who were in a social group in 2006 but found in another social unit in 2011. A higher proportion of males who were solitary in 2006 and had groups in 2011 than males who were in groups in 2006, became solitary, and were in a different group in 2011 would indicate that males need time to mature after emigrating (the former were solitary for a longer period of time than the latter), whereas if the opposite held it would indicate that high-quality males acquire groups more quickly than low-quality males.

We used rate-based $\chi^{2}$ calculations to compare the rates of terminations of dominant males in Bwindi versus the Virungas (Altmann and Altmann 1977). The termination rate equaled the number of dominant male terminations in each population (deaths plus usurpations), divided by the collective number of years that dominant males were observed in 
each population. Male tenure length can be estimated as the inverse of the termination rate (Dunbar 1984; Makarieva and Gorshkov 2004).

We also used rate-based $\chi^{2}$ calculations to compare the mortality rates for dominant males in each population. The mortality rate equaled the number of dominant males that died in each population, divided by the number of groupyears that were observed in each population (Janson and van Schaik 2000). The expected number of deaths was proportional to the number of male-years that each population was observed. Male-years equal the number of elapsed days from the beginning to the end of observations for each male, divided by 365.25 . These analyses included silverbacks of unknown age but excluded males that did not remain dominant long enough to sire any offspring (e.g., solitary males that acquired females for a few days or months before losing them again).

All statistical analyses were performed in $\mathrm{R}$, except for the rate-based $\chi^{2}$ calculations which were performed in Excel. Results were considered statistically significant if the $p$ value was less than 0.05 .

\section{Results}

\section{Immature males}

The main dataset contains five inter-group transfers by three immature males whose ages ranged from 6 to 12 years old. However, two of the males returned to their natal group ( 7 and 9 months later), so these were not permanent dispersal events. The remaining three dispersing immature males represent $4.4 \%$ of the 68 males who were observed in the study groups between the ages of 6-12. In addition, one male immigrated from an outside group at an estimated age six. There were no known cases of involuntary transfers by immature males in the main dataset, but only one of the study groups disintegrated at the very end of the study. One group disintegrated in the expanded dataset, and at least one immature male (age 9) made an involuntary transfer into a non-breeding group (along with three adult females and an infant).

\section{Subordinate males}

Among the 31 subordinate males who reached age 12 during the study, eight males (26\%) were still subordinates when observations ended. Among the other 23 males, 19 emigrated to become solitary ( $83 \%)$, three inherited the dominant role $(13 \%)$, and one become dominant during a group fission (4\%).
Considering emigrant males as those that became solitary and those that acquire groups via fissions as having dispersed, the 20:3 ratio of dispersal:philopatry at Bwindi was not significantly different from 15:7 ratio in the Virungas (LRT $=1.48, d f=1, p=0.22$ ). To examine if the proportion of males that became solitary differed between populations, we used a similar GLMM to compare the ratio of males who emigrated versus those who became dominant without emigration (males that become dominant via fissions were not considered as emigrants). The 19:4 ratio of emigration versus becoming dominant at Bwindi was not significantly higher than the $8: 8$ in the Virungas $(\mathrm{LRT}=2.51, d f=1, p=0.11$ ).

The average age of emigration was $14.3 \pm 1.0$ at Bwindi $(\mathrm{n}=7)$, which is not significantly different from $15.7 \pm 2.3$ years for eight males in the Virungas ( $\mathrm{LRT}=1.68, d f=1, p=0.19)$. The average age of becoming dominant was $15.0 \pm 1.7$ years at Bwindi $(n=3)$, which is not significantly different from $16.7 \pm 2.2$ years for eight males in the Virungas (LRT $=1.78, d f=1, p=0.18$ ). The probability of remaining subordinate (versus age) was significantly lower at Bwindi than in the Virungas (coefficient $=-0.95, z=-2.09, p=0.036$ ), suggesting that Bwindi males were more likely to either emigrate or become dominant at a younger age than in the Virungas (Fig. 3). Less than $10 \%$ of the males remain subordinate past age 18 at either site, which suggests that philopatry is not a common strategy unless the male becomes dominant.

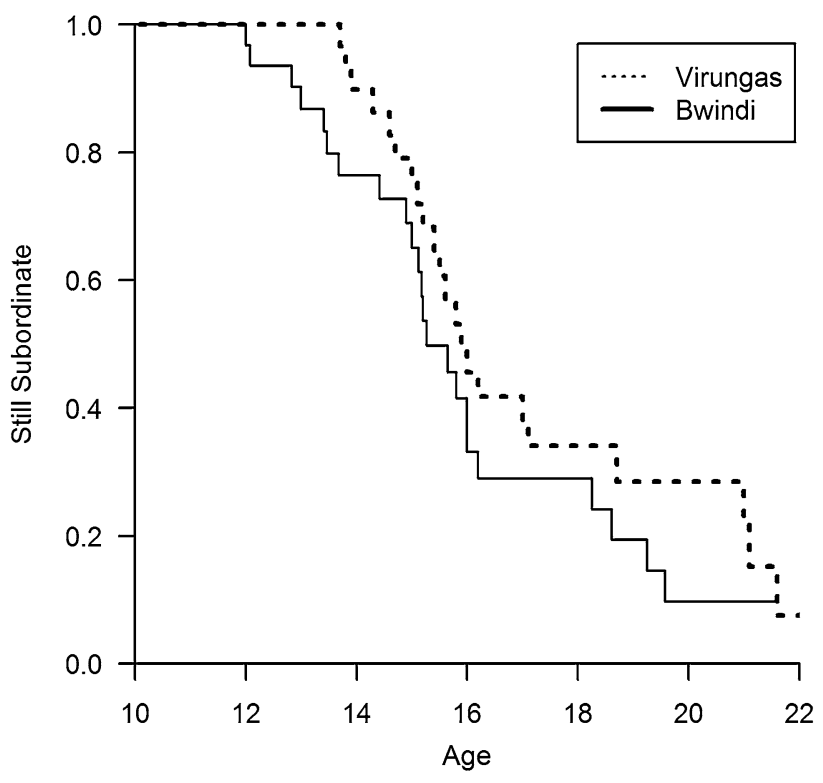

Fig. 3 Probability (versus age) for males to remain subordinate in the Virungas (dotted line) versus Bwindi (solid line) 


\section{Fate of solitary males}

The census data from 2006 and 2011 provides information on the fate of solitary males in two ways. First, we considered a cohort of 13 males who were identified in a breeding group in 2006 and were then found in a different social unit in 2011 (Table 1). Five of those 13 males were leading a new group in 2011, which suggests a 38\% initial success rate of group formation for dispersing silverbacks. The other eight males were solitary in 2011. Second, we identified ten solitary males in the 2006 census, of which six were still found in 2011. Only one of those six males had formed a new group (17\%), and the other five were still solitary. The success rate of group formation for those six emigrants is not significantly different from the 13 males who were previously identified in a group (Fisher's exact test, $p=0.34$ ), providing no evidence for the predictions that solitary males either acquire groups quickly or males require time to reach quality to attain groups. The six new groups contained an average of $4.5 \pm 2.0$ gorillas. All of the groups contained at least one female, and only one group contained more than one male.

\section{Dominance transitions}

After including groups when the entire composition was not fully known (Fig. 2), the expanded database includes portions of 25 dominance tenures. Nine of the dominance tenures had already begun when the groups were initially observed. Using the remaining 16 tenures to determine how they began, nine began when the previous alpha male died (56\%), five started when the group fissioned (31\%), and the other two began when a subordinate usurped the dominant position (13\%). One case of attaining alpha status (after the alpha male died) was by a male who immigrated into a breeding group as a fully mature silverback, which is the first reported case of such an immigration. To determine how tenures ended, 12 of the dominance tenures were ongoing at the conclusion of this study, so we considered the

Table 1 Genetic tracking of solitary and dispersing males from 2006 to 2011

\begin{tabular}{ll}
\hline 2006 & 2011 \\
\hline In breeding group (13) & Group leader $=5$ \\
& Solitary $=8$ \\
Solitary (10) & Group leader $=1$ \\
& Solitary $=5$ \\
& Not found $=4$ \\
\hline
\end{tabular}

Thirteen males that were in breeding groups in 2006 were tracked genetically in 2011 to be either group leaders or solitary. Ten males found as solitary in 2006 were found in 2011 as a group leader, solitary or not found other 13 tenures. Eleven tenures ended when the dominant male died (85\%) and the other two dominant males were usurped $(15 \%)$. Both of the usurped males became solitary after losing their alpha status; they subsequently died within 5 months of being usurped. In one case, the silverback had a badly injured leg that likely prevented him from keeping up with the group. Additionally, two visibly old subordinate males, who may have been deposed prior to the habituation of the group, repeatedly emigrated out of and immigrated into their group for more than 2 years.

The 11 deaths of dominant males occurred during 157.6 years of observed tenures, which represents a mortality rate of 0.070 deaths per year for dominant males. A mortality rate of 0.048 deaths per year has previously reported for dominant males in the Virungas (Robbins et al. 2013), which is not significantly different from the results from this study (rate-based Chi-square $=0.87, d f=1, p=0.35$ ). These results suggest that adult lifespans are not significantly longer for dominant males at Bwindi versus the Virungas.

Dominance tenures ended at a rate of 0.082 terminations per year, which is not significantly different than the corresponding rate of 0.064 for the Virungas (rate-based Chisquare $=0.54, d f=1, p=0.46$ ). The reciprocal of the termination rate equals 12.1 years at Bwindi (versus 15.7 years in the Virungas), which represents an estimate of the average dominance tenure length.

\section{Discussion}

Despite ecological variation between the two mountain gorilla populations and a longer interbirth interval in Bwindi compared to the Virunga Volcanoes (Robbins et al. 2009b), we found no difference between the two populations in the age of male dispersal, age of attaining alpha male rank, or male tenure length. A larger proportion of males emigrated to become solitary in Bwindi (83\%) than in the Virungas (about 50\%), but a larger sample size may be needed to detect a statistically significant difference. The lack of differences in age of dispersal and attaining alpha status is somewhat unexpected because the longer interbirth interval in Bwindi males would suggest a later weaning age and that they might attain full body size at a later age, leading to a delay in these life history markers. However, Bwindi males may not differ in their growth trajectories, they may compensate somehow in their growth trajectories during maturation, or Bwindi males may be smaller than Virunga males at maturity. An ongoing study examining body size and growth trajectories in the two populations will help resolve this issue. Similarly, the mortality rates of dominant males at Bwindi was not significantly higher than the Virungas, suggesting that adult lifespans are not significantly longer 
for dominant males at Bwindi versus the Virungas, so they do not provide evidence of a slower life history at Bwindi.

Alberts and Altmann (1995) suggest that a two-level process influences variance in life history traits and lifetime fitness of male baboons, specifically deterministic processes including maternal effects and demographic factors such as female availability and other competitive males, with stochasticity playing a larger role in the latter. In other words, environmental and/or maternal factors may affect the variation in age of maturation and survivorship, but the age of attaining dominance and reproductive success may be due to the opportunities available during a certain time window depending on the strength and number of competitors as well as the availability of females (Alberts and Altmann 1995; Kramer et al. 2017; van Noordwijk and van Schaik 2004). A similar pattern may be occurring in male mountain gorillas, with several pathways to attain alpha status, notably dispersal or philopatry, and female choice may play a strong role (see also Steenbeek et al. 2000). Females' choice of males via female dispersal is likely to be influenced by male size and strength (Breuer et al. 2012). However, females will be constrained by which males are available in the nearby vicinity since they only transfer during intergroup encounters with neighboring groups and during the limited time window when they are not pregnant nor have unweaned offspring vulnerable to infanticide (Robbins et al. 2009a, b).

Alpha rank acquisition by philopatric males may occur via usurpation or the death of the previous alpha male and some dispersing males become alpha via a group fission. Of the 16 males who acquired alpha status in Bwindi via those routes, $56 \%$ inherited it, $31 \%$ acquired it through group fission, and $13 \%$ usurped the previous alpha male. In comparison, of the eight males reported to become alpha at Karisoke (Stoinski et al. 2009a), 25\% inherited it, 37.5\% became alpha via a group fission, and $37.5 \%$ via usurpation. Given the small sample sizes, there is no apparent trend for one strategy being favored over another in either population, but it is apparent that males use all three tactics in both populations. Usurpation (challenges) was predicted to be the primary route to dominance acquisition for species with high paternity concentration (alpha male monopolizing most sirings) (van Noordwijk and van Schaik 2004), but in contrast, we found that usurpation was the least common tactic and that most dominance tenures ended when the male died. However, our results do support their prediction that males obtaining the alpha position via usurpation should be in their prime (van Noordwijk and van Schaik 2004), whereas males that become alpha following the death of the previous alpha male (succession) may have lower fighting ability (van Noordwijk and van Schaik 2004). If the alpha male in a multimale group dies, especially if due to stochastic events, a subordinate male may acquire alpha status sooner than he would if he had attempted to usurp the previous alpha male, which occurred twice in this study. One alpha male ( $\mathrm{RC}$ in Kyagurilo Group) was killed by lightning and the alpha male of another group died after falling more than $20 \mathrm{~m}$ from a tree (ND in Bitukura Group). In the first case (Kyagurilo Group), female choice further influenced the reproductive success of the new alpha male (RR, estimated to be in his mid-20's) as the group fissioned 1 year later, with four of seven females remaining with a young silverback (16 years old). Additionally, two females transferred out of RR's group in 2016, leaving him with only one adult female and many juveniles that he did not sire.

Attaining alpha status leads to large reproductive payoffs in mountain gorillas because males sire all offspring in one-male groups and roughly $85 \%$ in multimale groups (Bradley et al. 2005; Nsubuga et al. 2008; Vigilant et al. 2015). Average tenure length is $12-15$ years in both populations, with some males remaining dominant for 20 years or more (Robbins et al. 2013; Vigilant et al. 2015; this study). Therefore, male mountain gorillas have high monopolization potential for time periods spanning two, three, or more interbirth intervals.

We still lack sufficient data to determine how much demographic conditions and stochasticity influences the variance in the frequency of philopatry versus dispersal. Previous studies have struggled to explain which subordinate silverbacks will emigrate versus remain philopatric (Robbins 1995; Stoinski et al. 2009a; Watts 2000). Our current analyses suggest an answer: nearly all males emigrate unless they become dominant. Less than $10 \%$ of the males remain subordinate past age 18 at either site (Fig. 3), which suggests that philopatry is not a common strategy unless the male becomes dominant. From that perspective, mountain gorillas differ from species such as chimpanzees where philopatric males can remain subordinate for all/most of their adult lives.

The prospects for male mountain gorillas to become dominant probably depend on factors such as the relative strength of the males in the group, as well as random events that lead to the death of the dominant male. That may be one explanation for why quantitative factors such as group composition have been weak predictors of whether a male will emigrate (Stoinski et al. 2009a). Furthermore, subordinate males with more mating opportunities are more likely to remain philopatric (Stoinski et al. 2009b), suggesting that females can assess male quality and they preferentially mate with males who have a higher chance of becoming/ remaining dominant. It is also not surprising that emigrants have lower reproductive success than philopatric males because if males emigrate unless they become dominant, then philopatric males will almost always have reproductive success (whereas emigrants have no such certainty of acquiring females). If emigrants are the males who could not become dominant in their natal group, then they may 
typically have lower quality than the (philopatric) males who could become dominant. Thus the emigrants may merely be making the most of a bad job, and their lower success does not necessarily indicate that emigration is a poor reproductive strategy (Robbins and Robbins 2018).

The genetic tracking of dispersing males in this study provides some of the first information on the ability of these males to acquire mates and form new groups (see Hagemann et al. 2018 for western gorillas). Assuming that males did not briefly acquire females and then return to a solitary state if they all dispersed again, our results show that males may be solitary for as much as 5 years, suggesting either that they need a significant amount of time to continue developing before they are able to acquire groups or that there are few opportunities for these males. However, two of those silverbacks emigrated from a habituated group at ages 13 and 15 , and remaining solitary for less than 1-2 years, which illustrates that emigrants can form new groups relatively quickly and at relatively young ages, and further stresses the variability in male success. Our results about solitary males are comparable to those from Karisoke in which 27\% of dispersing males successfully formed groups (three out of 11 males whose fate was known 1-112 months after dispersing; Stoinski et al. 2009a). The results from both populations lend support to the results from modeling the Virunga population that dispersing males have lower reproductive success than philopatric males (Robbins and Robbins 2005).

Lastly, we also observed several novel events involving male dispersal. Specifically, immature males transferred into other heterosexual groups for some months and eventually return to their natal group. It is unclear why these males dispersed, but anecdotal evidence suggests that during intergroup encounters they may have been interacting with members of the other group and simply did not follow their natal group when the two groups separated at the end of the encounter. Nonetheless, these dispersal events by immature males may be one explanation for the occurrence of unrelated males co-residing in a group (Bradley et al. 2005). Two usurped males 'emigrated' from their group and died after a few months of being solitary. We also observed older, presumably deposed silverbacks repeatedly becoming solitary and rejoining their group, possibly because they could not always keep up with the group. Such events involving older silverbacks have not been documented in the Virungas and these cases show that not all solitary males in a population are in good enough physical condition to form new groups. We also report the first known case of a fully mature silverback immigrating into an established heterosexual group. These novel observations stress the value of long-term field studies for obtaining a comprehensive understanding of the flexibility in male life history strategies and primate grouping patterns (Clutton-Brock and Sheldon 2010; Janson 2000; van Noordwijk and van Schaik 2004).
Acknowledgements Open access funding provided by Max Planck Society. We thank the Uganda Wildlife Authority and the Uganda National Council for Science and Technology for permission and support for this work. We also thank the International Gorilla Conservation Programme, the Mountain Gorilla Veterinary Program, and Conservation through Public Health for their assistance with the 'Gorilla ID and Demography' project, particularly Fred Nizeyimana, and Stephen Venny Rubanga. Funding for the project was provided by Max Planck Society and Berggorilla Regenwald Direcktheilfe. This research was conducted in compliance with the regulations of the Uganda Wildlife Authority and the Uganda National Council for Science and Technology.

Open Access This article is distributed under the terms of the Creative Commons Attribution 4.0 International License (http://creativeco mmons.org/licenses/by/4.0/), which permits unrestricted use, distribution, and reproduction in any medium, provided you give appropriate credit to the original author(s) and the source, provide a link to the Creative Commons license, and indicate if changes were made.

\section{References}

Alberts SC (2012) Magnitude and sources of variation in male reproductive performance. In: Mitani J, Call J, Kappeler PM, Palombit RA, Silk JB (eds) The evolution of primate societies. University of Chicago Press, Chicago, pp 412-431

Alberts SC, Altmann J (1995) Balancing costs and opportunities: dispersal in male baboons. Am Nat 145:279-306

Altmann SA, Altmann J (1977) Analysis of rates of behaviour. Anim Behav 25:364-372

Bradley BJ, Robbins MM, Williamson EA et al (2005) Mountain gorilla tug-of-war: silverbacks have limited control over reproduction in multimale groups. Proc Nat Acad Sci 102:9418-9423. https://doi.org/10.1073/pnas.0502019102

Breuer T, Robbins AM, Boesch C, Robbins MM (2012) Phenotypic correlates of male reproductive success in western gorillas. J Hum Evol 62:466-472. https://doi.org/10.1016/j.jhevol.2012.01.006

Chapman CA, Rothman JM (2009) Within-species differences in primate social structure: evolution of plasticity and phylogenetic constraints. Primates 50:12-22. https://doi.org/10.1007/s1032 9-008-0123-0

Chowdhury S, Pines M, Saunders J, Swedell L (2015) The adaptive value of secondary males in the polygynous multi-level society of hamadryas baboons. Am J Phys Anthropol 158:501-513. https:// doi.org/10.1002/ajpa.22804

Clutton-Brock TH (2016) Mammal societies. Wiley, West Sussex

Clutton-Brock TH, Sheldon BC (2010) Individuals and populations: the role of long-term, individual-based studies of animals in ecology and evolutionary biology. TREE 25:562-573. https://doi. org/10.1016/j.tree.2010.08.002

Davidian E, Courtiol A, Wachter B, Hofer H, Horner OP (2016) Why do some males choose to breed at home when most other males disperse? Sci Adv 2:e1501236-e1501236. https://doi.org/10.1126/ sciadv. 1501236

Dobson FS (2013) The enduring question of sex-biased dispersal: Paul J. Greenwood's (1980) seminal contribution. Anim Behav 85:299-304. https://doi.org/10.1016/j.anbehav.2012.11.014

Dunbar RIM (1984) Reproductive decisions: an economic analysis of Gelada baboon social strategies. University of Princeton Press, Princeton

Furuichi T, Yamagiwa J, Aureli F (2015) Dispersing female primates. Springer, Tokyo 
Galban J, Abavandimwe D, Vakiener M et al (2017) Body growth and life history in wild mountain gorillas (Gorilla beringei beringei) from Volcanoes National Park, Rwanda. Am J Phys Anthropol 163:570-590. https://doi.org/10.1002/ajpa.23232

Gilroy JJ, Lockwood JL (2012) Mate-finding as an overlooked critical determinant of dispersal variation in sexually-reproducing animals. PLoS One 7:e38091. https://doi.org/10.1371/journ al.pone.0038091

Greenwood PJ (1980) Mating systems, philopatry and dispersal in birds and mammals. Anim Behav 28:1140-1162

Guschanski K, Vigilant L, McNeilage A, Gray M, Kagoda E, Robbins MM (2009) Counting elusive animals: comparing field and genetic census of the entire mountain gorilla population of Bwindi Impenetrable National Park, Uganda. Biol Cons 142:290-300. https://doi.org/10.1016/j.biocon.2008.10.024

Hagemann L, Boesch C, Robbins MM et al (2018) Long-term group membership and dynamics in a wild western lowland gorilla population (Gorilla gorilla gorilla) inferred using non-invasive genetics. Am J Primatol 80:e22898. https://doi.org/10.1002/ ajp. 22898

Harcourt AH (1978) Strategies of emigration and transfer by female primates, with special reference to mountain gorillas. Zeit Tierpsychol 48:401-420

Janson CH (2000) Primate socio-ecology: the end of a golden age. Evol Anthropol 9:73-86

Janson CH, van Schaik CP (1993) Ecological risk aversion in juvenile primates: slow and steady wins the race. In: Pereira ME, Fairbanks LA (eds) Juvenile primates: life history, development, and behavior. Oxford University Press, New York, pp 57-74

Janson CH, van Schaik CP (2000) Infanticide by males and its implications. University of Cambridge Press, Cambridge

Jiang J (2007) Linear and generalized linear mixed models and their applications. Springer, Berlin

Kalpers J, Williamson EA, Robbins MM, McNeilage A, Nzamurambaho A, Lola N, Mugiri G (2003) Gorillas in the crossfire: population dynamics of the Virunga mountain gorillas over the past three decades. Oryx 37:326-337. https://doi.org/10.1017/ s0030605303000589

Kappeler PM, van Schaik CP (2002) Evolution of primate social systems. Int J Primatol 23:707-740

Koenig A, Borries C (2012) Social organization and male residence pattern in Phayre's leaf monkeys. In: Kappeler PM, Watts DP (eds) Long-term field studies of primates. Springer, Berlin, pp 215-236

Kramer KL, Schacht R, Bell A (2017) Adult sex ratios and partner scarcity among hunter-gatherers: implications for dispersal patterns and the evolution of human sociality. Philos Trans R Soc B 372:20160316. https://doi.org/10.1098/rstb.2016.0316

Makarieva AM, Gorshkov VG (2004) On the dependence of speciation rates on species abundance and characteristic population size. J Biosci 29:119-128

Nsubuga AM, Robbins MM, Boesch C, Vigilant L (2008) Patterns of paternity and group fission in wild multimale mountain gorilla groups. Am J Phys Anthropol 135:263-274. https://doi. org/10.1002/ajpa.20740

Onyango PO, Gesquiere LR, Altmann J, Alberts SC (2013) Puberty and dispersal in a wild primate population. Horm Behav 64:240-249. https://doi.org/10.1016/j.yhbeh.2013.02.014

Ostro LE, Silver SC, Koontz FW, Horwich RH, Brockett R (2001) Shifts in social structure of Black Howler (Alouatta pigra) groups associated with natural and experimental variation in population density. Int J Primatol 22:733-748

Pankratz VS, de Andrade M, Therneau TM (2005) Random-effects Cox proportional hazards model: General variance components methods for time-to-event data. Gen Epidem 28:97-109. https:// doi.org/10.1002/gepi.20043
Port M, Johnstone RA, Kappeler PM (2012) The evolution of multimale groups in Verreaux's sifaka, or how to test an evolutionary demographic model. Behav Ecol 23:889-897. https://doi. org/10.1093/beheco/ars053

Pusey A (2012) Magnitude and sources of variation in female reproductive performance. In: Mitani J, Call J, Kappeler PM, Palombit RA, Silk JB (eds) The evolution of primate societies. University of Chicago Press, Chicago, pp 343-366

Pusey AE, Packer C (1987) Dispersal and philopatry. In: Smuts BB, Cheney DL, Seyfarth RM, Wrangham RW, Struhsaker TT (eds) Primate societies. University of Chicago Press, Chicago, pp 250-266

Robbins MM (1995) A demographic analysis of male life history and social structure of mountain gorillas. Behaviour 132:21-47. https://doi.org/10.1163/156853995x00261

Robbins AM, Robbins MM (2005) Fitness consequences of dispersal decisions for male mountain gorillas (Gorilla beringei beringei). Behav Ecol Sociobiol 58:295-309. https://doi. org/10.1007/s00265-005-0917-7

Robbins MM, Robbins AM (2018) Variation in the social organization of gorillas: life history and socioecological perspectives. Evo Anthropol 27:218-233. https://doi.org/10.1002/evan.21721

Robbins AM, Robbins MM, Gerald-Steklis N, Steklis HD (2006a) Age-related patterns of reproductive success among female mountain gorillas. Am J Phys Anthropol 131:511-521. https:// doi.org/10.1002/ajpa.20474

Robbins MM, Nkurunungi JB, McNeilage A (2006b) Variability in the feeding ecology of eastern gorillas. In: Hohmann G, Robbins MM, Boesch C (eds) Feeding ecology in apes and other primates. University of Cambridge Press, Cambridge, pp 25-47

Robbins AM, Stoinski TS, Fawcett KA, Robbins MM (2009a) Does dispersal cause reproductive delays in female mountain gorillas? Behaviour 146:525-549. https://doi.org/10.1163/156853909x 426354

Robbins MM, Gray M, Kagoda E, Robbins AM (2009b) Population dynamics of the Bwindi mountain gorillas. Biol Conserv 142:2886-2895. https://doi.org/10.1016/j.biocon.2009.07.010

Robbins AM, Gray M, Basabose A et al (2013) Impact of male infanticide on the social structure of mountain gorillas. PLoS One 8:e78256. https://doi.org/10.1371/journal.pone.0078256

Robbins AM, Gray M, Breuer T, Manguette M et al (2016) Mothers may shape the variations in social organization among gorillas. R Soc Open Sci 3:160533. https://doi.org/10.1098/rsos.160533

Roy J, Vigilant L, Gray M et al (2014) Challenges in the use of genetic mark-recapture to estimate the population size of Bwindi mountain gorillas (Gorilla beringei beringei). Biol Conserv 180:249-261. https://doi.org/10.1016/j.biocon.2014.10.011

Seiler N, Boesch C, Stephens C, Ortmann S, Mundry R, Robbins MM (2018) Social and ecological correlates of space use patterns in Bwindi mountain gorillas. Am J Primatol 80:e22754. https://doi.org/10.1002/ajp.22754

Steenbeek R (2000) Infanticide by males and female choice in wild Thomas's langurs. In: van Schaik CP, Janson CH (eds) Infanticide by males and its implications. Cambridge University Press, Cambridge, pp 251-289

Sterck EH (1999) Variation in langur social organization in relation to the socioecological model, human habitat alteration, and phylogenetic constraints. Primates 40:199-213

Stoinski TS, Vecellio V, Ngaboyamahina T, Ndagijimana F, Rosenbaum S, Fawcett KA (2009a) Proximate factors influencing dispersal decisions in male mountain gorillas, Gorilla beringei beringei. Anim Behav 77:1155-1164. https://doi.org/10.1016/j. anbehav.2008.12.030

Stoinski TS, Rosenbaum S, Ngaboyamahina T, Vecellio V, Ndagijimana F, Fawcett KA (2009b) Patterns of male reproductive behaviour in multi-male groups of mountain gorillas: examining 
theories of reproductive skew. Behaviour 146:1193-1215. https ://doi.org/10.1163/156853909X419992

van Noordwijk MA, van Schaik CP (2001) Male migration and rank acquisition in wild long-tailed macaques Macaca fascicularies. Behaviour 138:849-961

van Noordwijk MA, van Schaik CP (2004) Sexual selection and the careers of male primates: paternity concentration, dominanceacquisition tactics and transfer decisions. In: Kappeler PM, van Schaik CP (eds) Sexual selection in primates. Cambridge University Press, Cambridge, pp 208-229

Vigilant L, Roy J, Bradley BJ, Stoneking CJ, Robbins MM, Stoinski TS (2015) Reproductive competition and inbreeding avoidance in a primate species with habitual female dispersal. Behav Ecol Sociobiol 69:1163-1172. https://doi.org/10.1007/s0026 5-015-1930-0
Watts DP (2000) Causes and consequences of variation in male mountain gorilla life histories and group memebership. In: Kappeler PM (ed) Primate males. Cambridge University Press, Cambridge, pp 169-179

Wright E, Grueter CC, Seiler N, Abavandimwe D et al (2015) Energetic responses to variation in food availability in the two mountain gorilla populations (Gorilla beringei beringei). Am J Phys Anthropol 158:487-500. https://doi.org/10.1002/ajpa.22808

Publisher's Note Springer Nature remains neutral with regard to jurisdictional claims in published maps and institutional affiliations. 